Int. J. Morphol.,

32(3):935-941, 2014.

\title{
Histological Changes Implicated in Metastasis
}

\author{
Cambios Histológicos Implicados en Metástasis
}

Roberto Díaz-Peña* \& Patricia Castro-Santos*

\begin{abstract}
DÍAZ-PEÑA, R. \& CASTRO-SANTOS, P. Histological changes implicated in metastasis. Int. J. Morphol., 32(3):935-941, 2014.
SUMMARY: The process of malignancy emergence is associated with the acquisition of the capacity to invade other tissues. Several different biological processes have been described as involved in this process. Specifically, epithelial mesenchymal transition (EMT), a mechanism associated with embryogenesis and wound repair but also with mobility acquisition, is one of the concerned processes. In EMT an epithelial cell loses its epithelial characteristics, its junctions with neighbor cells and with the basal lamina and acquires mobility and mesenchymal characteristics. Also, factors of the tumor microenvironment have been described as involved. Tumor presence triggers a response in the surrounding tissue known as reactive stromal. It shows particular characteristics similar to those found in wound healing stroma: an increase of the fibroblast number and enhancing of the capillary density. The notable difference is the chronicity in the tumoral process. Of a high relevance seems to be the role of activated macrophages with a characteristic phenotype. Finally, cancer associated fibroblasts (CAF) are a type of cells found in tumors, developed from local tissue or possibly from bone marrow. CAF characteristically show a distinct morphology and secrete a high number of metalloproteases allowing tumoral cells advance through the tissue. Additionally, CAF have a direct effect on the survival of the epithelial cells. The three processes are interrelated and metastasis is probably caused by the effect of all of them and probably by other additional factors.
\end{abstract}

KEY WORDS: EMT; CAF; Metastasis; Cancer; Inflammation.

\section{INTRODUCTION}

Tumor development has been described as the result of accumulative mutation events. Fearon \& Vogelstein defined this concept in terms of the adenoma- carcinoma sequence: an early neoplastic lesion leads to a benign adenoma and finally to a malignant adenocarcinoma because of B-RAF, RAS and p53 mutations. Meanwhile, malignancy emergence is associated with the acquired capacity to invade other tissues. In this case the tumor becomes heterogeneous and some cells are able to separate from others and spread into other tissues. When these cells reach the blood through the lymph vessels, the dissemination can reach distant tissues.

There is a great interest in identifying the biological process involved in the acquisition of mobility and invasivity. Currently, studies are focused on three mechanisms: epithelial- mesenchymal transition (EMT), tumor microenvironment influence and activated fibroblasts present in tumoral desmoplastic reaction, the cancer associated fibroblasts (CAF). These three mechanisms are totally interrelationed and we cannot separate the influence of one process from the influence of the other. Especially, since the same molecules are involved in different processes.
Different studies carried out on several human tumors have tried to identify in vivo, genes implicated in the metastasis process. Specifically, a study comparing ovarian carcinoma samples with metastatic ovarian carcinoma by expression arrays showed 156 genes with differential expression (Bignotti et al., 2007).

In a later study, data from samples of ovarian carcinoma in different stages from The Cancer Genome Atlas were analyzed together. A strong association between advanced stage and overexpression of a genes core, all of which are implicated in desmoplastic reaction of the stromal and EMT, was found. The overexpressed genes included fibroblast activation protein (FAP), actin alpha 2 (ACTA2) or several collagens, remarkably COLL11A1, metalloproteinases, specifically matrix metalloproteinase11 (MMP11) and cadherins, overall cadherin 11(CDH11). This expression profile is the same as a particular type of CAF described as metastasis associated fibroblast (MAF) (Kim et al., 2010). These results were replicated in samples of tumors from other origins (colon, gastric, breast) finding a similar association. Therefore, the genetic profile found in metastatic samples supports the theory of the implication of

* Facultad de Ciencias de la Salud, Universidad Autónoma de Chile, Talca, Chile.

Grant N ${ }^{\circ} 36$, Universidad Autónoma de Chile. 
the three mentioned process in the acquisition of invasivity and metastasis.

EMT. EMT is a biological process that allows epithelial cell anchored to the basal membrane to assume a mesenchymal cellular phenotype, by multiple biochemical changes. These changes include an increase in their capacity for migration, invasivity and apoptosis resistance and a high increment in the production of extracellular matrix components. EMT is implicated in physiological processes such as implantation, embryogenesis or organs development (Type 1 EMT), as well as tissue repair and fibrosis (Type 2 EMT). During this process, epithelial cells stop the expression of epithelial markers such as E-cadherin, cytokeratin, zona occludens 1 , laminin 1 or entactin and activate the expression of mesenchymal markers such as FAP, N-cadherin, vimentin, fibronectin, b-catenin or a5b1-integrin. The transition from epithelial cell to mesenchymal cell obviously causes its separation from basal membrane and the acquisition of mobility. Evidently, this process is not all or nothing, as it implicates a sequence of events with several intermediate steps associated with differential markers expression of both extremes: epithelial and mesenchymal.

Apart from the organ formation, EMT plays an important physiological role. When the organ is finally developed, the final differentiation of the epithelial cells allows them to maintain the epithelia structure and specific function through their high specialization. In this environment, the role of the mesenchymal cell seems to be secondary. However, processes associated to tissue reparation and relationed with pathological stress, specifically with inflammation, need this mechanism to recover the integrity of the epithelium when it is disturbed.

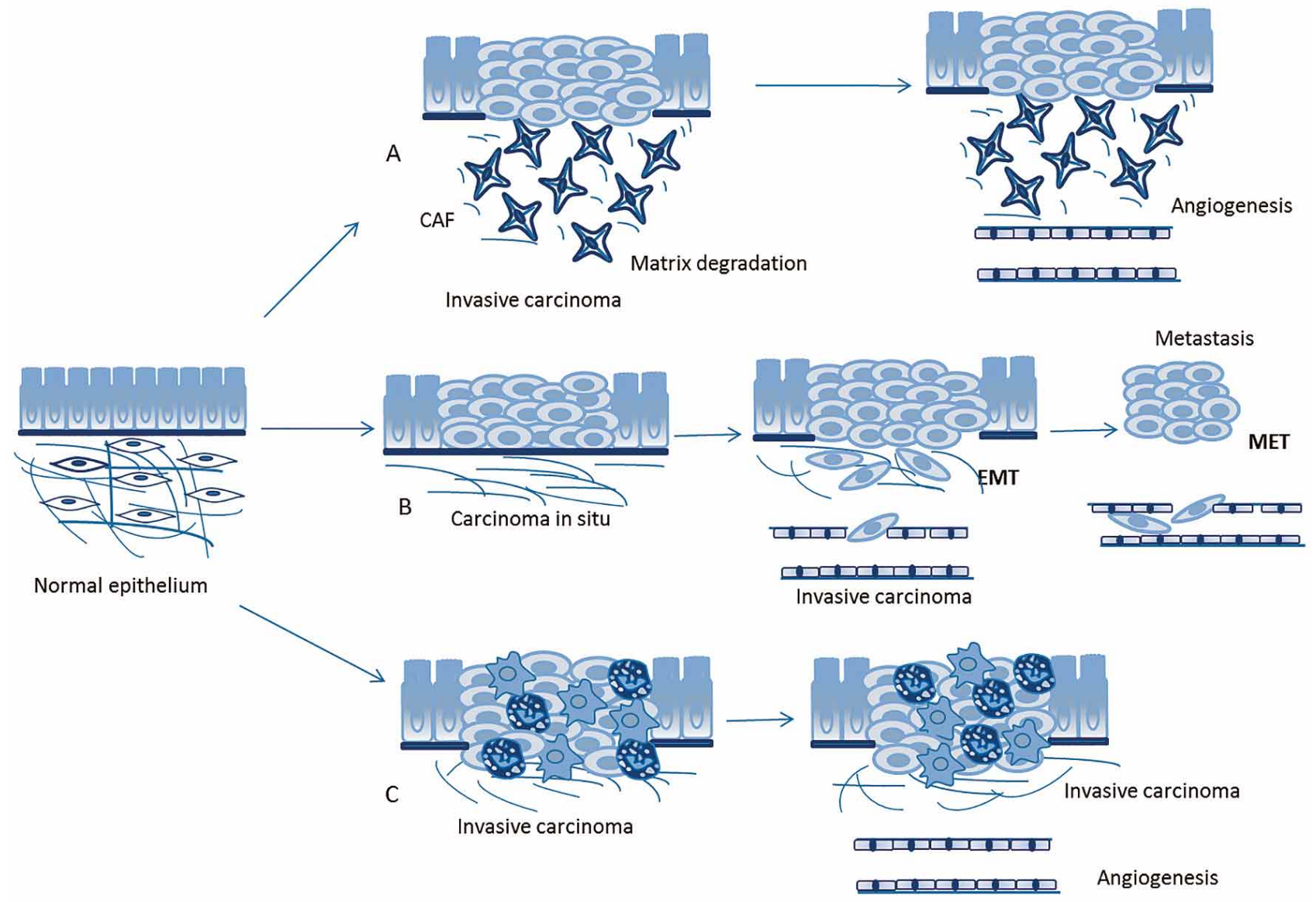

Fig. 1. A. Tumoral process causes CAF appearance. CAF are characterized by morphological differences with normal fibroblasts, alphaSMA expression and metalloproteinases secretion. Metalloproteinases promote the matrix degradation favoring the tumoral cells advance. CAF also increase the angiogenesis allowing tumoral cells to reach the blood; B. EMT process allows an epithelial cell to acquire mobility. Epithelial cell experimenting EMT progressively decreases its expression of epithelial markers and increase the mesenchymal ones. This causes its detaching of the basal membrane and the acquisition of mobility allowing it to reach the blood and distant tissues. In the new location, the reverse process, MET, will develop a epithelial cell with the same characteristics of the original, therefore a metastasis; C. The microenvironment of the tumor is a complex system formed by endothelial cells, smooth muscle cells, pericytes, fibroblasts and immune system cells. Unresolved inflammation causes an increase of epithelial cells survival and angiogenesis. 
For this, a complementary process, the transition from mesenchymal cell to epithelial cell (MET), is needed. Type 2 EMT, associated to wound healing and tissue regeneration, stop when inflammation decreases. Sometimes, inflammation is chronic and the maintenance of the response causes fibrosis development. This process has been also associated with implication of the desmoplastic reaction of the stroma and metastasis capacity.

A third type of EMT has been directly associated with cancer progression and metastasis (Yang \& Weinberg, 2009). The first step for tissue invasivity is the separation of the tumoral cell from the basal membrane. This requires modifications in the junctions between cells and with the extracellular matrix, important changes in the cytoskeleton and an increase in its mobility. All of this occurs by an EMT process. Studies performed in mice and in vitro cell culture have shown the presence of carcinoma cells with a mesenchymal phenotype and expression of mesenchymal markers as smooth muscle actin alpha (a-SMA), fibroblastspecific protein 1 (FSP1), vimentin or desmin. These cells appear typically in the front of the tumor and probably then reach the vessels and are carried by the circulation and extravasated to other tissues whereby the MET originates the metastasis. In the MET process, the transient mesenchymal cell recovers its precedent characteristics giving a same type of tumoral cell to the original (Zeisberg et al., 2009).

Morphologically, EMT is characterized by the loss of the typical apical- basal polarity of the epithelial cells and the strong union with the adjacent cells. An anteriorposterior polarity is developed associated with mobility acquisition, the typical fusiform morphology and an interaction with the surrounding matrix including protrusions development. All of these characteristics allow the advance of the cell through the extracellular matrix (Adams, 2001). In these interactions the integrins contacting with actin and the intermediate filaments are mainly involved. At the same time the movement of the tumoral cell through the extracellular matrix requires the action of proteases. Specifically, metalloproteases anchored to the membrane play a key role. These metalloproteases are highly overexpressed in EMT and are able to activate this process (Mohamed et al., 2006).

Expression studies show an association between EMT and "cadherin switching", consisting in a progressive loose of the E-cadherin (CDH1) expression and an increment in N- and OB-cadherin or cadherin-11 (CDH11). Other proteins present in epithelial cellular junctions as claudins, occludins or conexins are also associated with EMT (Voulgari et al., 2009). EMT also requires a rearrangement of the cytoskeleton particularly dramatic in the case of the intermediate filaments since it implies great changes as the loss of expression of keratins, typically epithelial, and the new expression of vimentins, characteristic of mesenchymal cells (Omary et al., 2004). Other molecule associated with EMT is the fibroblast specific protein FSP-1/S100A4, a component of the superfamily of calcium binding proteins implicated in the changes of the cytoskeleton.

These changes produced in EMT are controlled by the increased expression of transcription factors as SNAI1 (Snail), SNAI2 (Slug), TWIST1 (Twist) and ZEB2 (SIP1) (Zeisberg et al.).

Recently, a number of genes coordinately coexpressed in EMT have been described, defining an "EMT core signature". This consists in the down- regulation of 159 genes, including the E-cadherin, and the up- regulation of 87 genes, being the most remarkably the $\mathrm{N}$ - cadherin, vimentin and the matrix metalloproteinase 2 (MMP2). Interestingly, studies performed on tumor samples of different origin (breast, ovarian, colon, neuroblastoma) showed a number of genes overexpressed in all of them. Remarkably, among these overexpressed genes is Slug, a transcription factor associated with EMT, several collagens, overall COL11A1, proteinases and a high number of matrix glycoproteins, suggesting that an EMT process has occurred in the tumor. Specifically, this profile of overexpressed genes in tumoral cell included 17 genes described as typical from the "EMT core signature". Among them, CDH11, ACTA2 (aSMA, alpha smooth muscle actin), SNAI2 and VIM stand up (Anastassiou et al., 2011).

EMT does not happen in all tumor cells. On the contrary, it would be a process occurring in a much reduced number of cells. This is an important limitation of the study of these processes: the low percentage of implicated cells makes it difficult to study and follow up.

EMT induction depends on a high number of factors. Among them it is supposed to be involved the Wnt pathway, hedgehog pathway, cytokine transforming growth factor beta (TGFb), Notch or nuclear factor kappa B (NF-kB) (Song et al., 2007). Anyway, EMT induction seems to be associated to stroma molecules, specifically hepatocyte growth factor (HGF), epidermal growth factor (EGF), platelet derived growth factor (PDGF) and TGF-b. These molecules induce the expression of transcription factors as Snail, Slug, ZEB1, Twist, Goosecoid and FOXC2. Signal transduction is mediated by proteins as ERK, MAPK, PI3K, Akt, Ras, or c-Fos and surface proteins as b4 integrins, a5b1-integrin or aVb6-integrin (Tse et al., 2007). 
Other key protein in the involvement of the EMT with the metastasis progression is E-cadherin. It has been described that the loss of E-cadherin expression is associated with poor prognostic, tumor progression and metastasis (Kowalski et al., 2003). E-cadherin expression is controlled by SNAI1, SNAI2, ZEB1 and ZEB2, transcription factors associated to EMT development.

Tumor microenvironment. It is generally accepted that tumor growth is not just determined by malignant cells but also by the tumor stroma. However, is the stroma involved in the metastasis process? Recent studies indicate that it is. Stroma around tumoral cells shows particular characteristics similar to those found in wound healing stroma. These differences with the normal stroma classify it as reactive stroma, characterized by an increase of the fibroblast number and enhancing of the capillary density. The tumor microenvironment is a complex system formed by many cellular types, including endothelial cells, smooth muscle cells, pericytes, different types of fibroblasts, myofibroblasts and a high diversity of cells from the immune system (Albini et al., 2007).

Experiments from several authors have described the presence of mesenchymal cells of tumoral origin in blood very early in the tumoral process, even in premalignant stage (Rhim et al., 2012). Similar results were found in breast cancer studies where "slept" EMT cells were found in the perimeter of infiltrate ductal carcinomas (Raviraj et al., 2012). This process seems to be inflammation dependent since it is avoided by the administration of dexamethasone, an anti-inflammatory agent (Rhim et al.).

The role of the inflammation in the development and progression of cancer has been extensively studied. Microenvironment concept was described for the first time as soon as XIX century in the "seed and soil" theory by Paget. However, recent data show not only an implication of the interaction of the tumor with the endothelial cells but also with the stromal cells surrounding the tumor, including inflammatory cells. The inflammatory process consists in a serial of reactions including the pathogen elimination and the tissue remodeling. In a crucial point the aggressive reaction against the pathogen, and frequently against the host tissues, becomes into response characterized by the mesenchymal cells activation, production of collagen and other components of the matrix, tissue regeneration and new vessels formation. In the carcinogenesis the absence of a chronic inflammatory process resolution, produce an alteration in this sequence and homeostasis is never reached. In this situation, the alteration of the process promotes the tumor growth by the activation of the stroma surrounding and the neovascularization. The continuous hyperplasia and dysplasia promotes the neoplastic development. This theory postulates that the tumor is a wound that never heals (Dvorak, 2005). Cells participating in the inflammatory reaction and normally driving to a damage resolution react paradoxically to the presence of epithelial cells promoting their survival, replication and angiogenesis (Albini et al.). In this way, control mechanisms of the epithelial cells dysfunction by the stromal cells have been described. These mechanisms would be the responsible of the evolution from hyperplasia to a cancerous process. Data supporting this theory are the finding of an important phenotypic difference between normal macrophages (M1) and tumor associated macrophages (TAM) (M2). Moreover, even the number of TAM has been correlated with the prognosis of several cancers being worst when the number is higher. Determined cytokines, as IL-4 and IL-10, polarize TAM through M2 phenotype. This phenotype is characterized by the low capacity of antigen presentation, produced by factors avoiding $\mathrm{T}$ cells proliferation, and a higher cellular debris elimination activity, angiogenesis and tissue remodeling (Lewis et al., 2006). Additionally, it has been described that inflammation induces EMT in animal models (Rhim et al.). To sum up, inflammation may promote cancer progression through its effect in the primary site and also by facilitation of cells access to the circulation. Adipocytes around the tumor have been also described with a high relevance. Studies of transplanting tumoral cell in mice showed that the cells from human origin suffer expression changes compatible with EMT. At the same time, in cells from mouse tissue the expression of adipocytes markers decreases (Anastassiou et $a l$.). This loss of differentiation may promote the tumoral cells migration. Some authors identify these processes with acquisition of stem cell characteristics and, therefore, they consider this process associated to the tumoral stem cells (Mani et al., 2008). The consequence is the development of a stromal reaction to the tumor. The process is promoted mainly by the vascular endothelial growth factor (VEGF) released by fibroblasts and inflammatory cells. VEGF produces extravasation of plasma containing proteins as fibrin. Fibroblasts and inflammatory and endothelial cells are attracted so the angiogenesis of the tumor is promoted. Epithelial carcinomas cells are separated from the stroma by basal membrane. When the carcinoma becomes invasive, basal membrane is degraded and the activated stroma takes contact with the tumoral cells increasing the stromal influence. However, even when tumoral cells are separated from the stroma by the basal membrane, communication between them exists.

Invasive carcinoma is associated with desmoplastic, an increased deposition of extracellular matrix (ECM) molecules. Between the ECM molecules, tenascin-c and hyaluronic acid are associated to a higher invasivity. 
Therefore, ECM produced by fibroblasts, influence on the invasion capacity of the tumor. ECM deposition also conditions the growth factors availability and the interaction with cells through integrins.

Reactive stroma is produced as a consequence of the effect of TGFbeta, PDGF and fibroblast growth factor 2 (FGF2) released by cancer cells over the fibroblast. Probably, it reflects an attempt of containing the cancerous lesion. High angiogenesis in the stroma is also produced by the stromalcell-derived factor 1 (SDF1), a chemokine with an additional direct effect over the tumoral cells. Specifically, SDF1 increases the proliferation of the cancer cells.

CAF. Regarding the implication of CAF in metastasis a high number of studies have been developed. These fibroblasts have been denominated peritumoral fibroblasts, fibroblasts from the reactive stroma or cancer associated fibroblasts. Characteristically, CAF are activated fibroblasts within desmoplastic lesions that are associated with malignant tumors and often express alpha- smooth muscle actin. Fibroblasts have been described as no-vascular, no-epithelial, no- inflammatory cells present in the connective tissue and are its main cellular component. Its functions are the formation of the main part of the extracellular matrix, the regulation of the epithelial differentiation, the control of the inflammation and they are also implicated in wound healing. Fibroblasts also synthetizes metalloproteases, implicated in matrix degradation. When the tissue damage happens, fibroblasts activate and participate in the reparation process. When the damage is continuous, fibrosis is developed. Activated fibroblasts produce a higher number of matrix components and proliferate quicker than those from the healthy tissue. After reparation, activated fibroblasts disappear. In fibrosis and in tumor formation, fibroblasts keep constantly activated. Activated fibroblasts are characterized by an increase of the collagen I, tenascin, EDA- fibronectin (extra domain containing - fibronectin) and SPARC (secreted protein acidic and rich in cysteine) secretion. Frequently, as it was mentioned before, CAF expresses smooth muscle alpha actin.

CAF number is very high in stroma associated tumors of breast, lung, colon and pancreas. CAF activation is mediated by MCP1 (Monocyte chemotactic protein-1), matrix degradation proteinases and TGFbeta (transforming growth factor beta). Their role as activators of tumor growth and angiogenesis through CXCL12 expression, a known ligand of CXCR4 chemokines receptor has been demonstrated. Additionally, CAF synthetize metalloproteinases. These enzymes promote the matrix degradation and facilitate advance of the tumoral cells. CAF show a different phenotype compared with normal fibroblasts which do not express CXCL12, and neither induce angiogenesis or hardly any tumor growth (Orimo et al., 2005). Indeed, CAF chemokine secretion from breast tumor induces proliferation and migration of the tumoral cells (Orimo et al.). Results from our laboratory showed a high expression of COL11A1 in peritumoral myofibroblasts from breast cancer. It was also confirm in pancreatic adenocarcinoma where a high overexpression of COL11A1 was found by DNA microarrays of these tumor samples, corresponding with a very specific immunostaining of peritumoral fibroblasts being negative in normal tissue, tumoral cells and benign inflammatory reaction (GarcíaOcaña et al., 2012). Experiments injecting immortalized prostate epithelial cells in mice showed that only when CAF were injected at the same time, tumor developed and not when normal fibroblasts were used. One theory about activated fibroblasts associate them with the EMT process, again relating two processes described as implicated in metastasis. Several different origins have been described for CAF, both from local resident tissues and bone marrow. Probably, CAF reflects a heterogeneous cellular type derived from more than one cell type. One of these may be an epithelial cell through an EMT process (Kalluri et al., 2009). For example, it was described that $30 \%$ of the activated fibroblast in kidney fibrosis are derived from tubular epithelial cells by EMT. However it is not clear the origin of the cells suffering EMT in a tumor. In studies developed by xenotransplantation of tumoral human cells to immunosuppressed mice, a profile of genes activation associated with EMT expression through Slug transcription factor was found in human cells, therefore, tumoral cells, but it was accompanied by a decrease of adipocytes markers in mouse cell, then stromal tissue (Anastassiou et al.). Therefore, the cells in EMT process may be cancer stem cells or tumoral cells under the influence of the adipocytes of the stroma. A theory accepted by many authors postulates that EMT may convert cancer cells into mesenchymal, fibroblast- like cells that may well assume the duties of CAF.

Again, in these studies, COL11A1 played an important role. However, studies carried out by us in tumoral cell lines as A549, MDA-MB231, CAPAN or HT29 exposed to TGFb in order to activate the EMT, did not show an increase of COL11A1 expression by immunohistochemistry using a monoclonal antibody developed in our facilities (García-Ocaña et al.). Probably, this result is due to the small percentage of cells suffering from EMT.

Regarding the mechanisms associated to $\mathrm{CAF}$ involvement in metastasis, metalloproteases secretion may be crucial. Metalloproteases act over the extracellular matrix allowing tumoral cells to migrate through it and reach the circulation. Also, it is clearly remarkable that CAF influences 
on angiogenesis and chemokine secretion increases. Additionally, cooperation between normal fibroblast and immune system preventing tumorigenesis has been described. This anti-tumoral mechanism might be the CAF loss (Cheng et al., 2005). Finally, recent reports have indicated a relevant role for $\mathrm{CAF}$ in the modulation of cancer stem cells (Malanchi et al., 2012).

\section{CONCLUSION}

Although the first hypothesis about metastasis origin were based in an accumulation of mutations until one of them provides the invasivity and metastasis capability, nowadays, this theory is into abeyance, as it is believed that the metastatic power is acquired sooner. This is supported by the data of metastasis development years after extirpation of small tumors with no evidence of metastasis at the diagnosis (Pantel et al., 2008). Also the presence of metastasis without evidence of a primary tumor (Greco \& Hainsworth, 2009) makes it easier to refuse this "Darwinian" theory. By now, it is believed that the appearance of cells capable of origin metastasis is independent of the tumor evolution and it could happen in the first stages of the tumoral process, even in precancerous lesions (Rhim et al.). Experiments made in pancreatic cancer murine models, by marking the cells from pancreatic origin, showed the presence of tumoral mesenchymal cells, originated inside the pancreas, in the blood in very early phases of the tumoral evolution, even when only precancerous lesions are present (Rhim et al.). The process has been describes as a consequence of several mechanisms where inflammation was crucial, as it is avoided by dexamethasone, and probably CAF are generated by an EMT process.

DÍAZ-PEÑA, R. \& CASTRO-SANTOS, P. Cambios histológicos implicados en metástasis. Int. J. Morphol., 32(3):935-941, 2014.

RESUMEN: El desarrollo de malignidad está asociado con la adquisición de la capacidad de invadir otros tejidos. Varios procesos diferentes han sido asociados con la aparición de metástasis. Concretamente, la transición epitelio mesénquima (TEM), un mecanismo asociado con embriogénesis y reparación de heridas pero también con adquisición de movilidad, es uno de ellos. En la TEM, una célula epitelial pierde sus características epiteliales, sus uniones con las células vecinas y con la lámina basal y adquiere movilidad y características mesenquemáticas. También han sido asociados factores del microambiente del tumor. La presencia del tumor produce una respuesta en el tejido que lo rodea descrito como estroma reactivo. Sus características son similares a las del estroma de las heridas en proceso de curación: un incremento del número de fibroblastos y un aumento de la densidad de capilares. La gran diferencia es la cronicidad del proceso tumoral. De gran relevancia es el papel de los macrófagos activados que muestran un fenotipo característico. Finalmente, los fibroblastos asociados a cáncer (FAC) son un tipo de células encontradas en tumores, que se desarrollan a partir del tejido local o quizá de la médula ósea. Los FAC, de modo característico muestran una morfología diferente y secretan una gran cantidad de metaloproteasas permitiendo a la célula tumoral avanzar a través del tejido. Además, los FAC ejercen un efecto directo sobre la supervivencia de las células epiteliales. Los tres procesos están interrelacionados y la metástasis es causada probablemente por el efecto de todos ellos y probablemente por otros factores adicionales.

PALABRAS CLAVE: EMT; CAF; Metástasis; Cáncer; Inflamación.

\section{REFERENCES}

Adams, J. C. Cell-matrix contact structures. Cell. Mol. Life Sci., 58(3):371-92, 2001.

Albini, A. \& Sporn, M. B. The tumour microenvironment as a target for chemoprevention. Nat. Rev. Cancer, 7(2):139-47, 2007.

Anastassiou, D.; Rumjantseva, V.; Cheng, W.; Huang, J.; Canoll, P. D.; Yamashiro, D. J. \& Kandel, J. J. Human cancer cells express Slug-based epithelial-mesenchymal transition gene expression signature obtained in vivo. BMC Cancer, 11:529, 2011.

Bignotti, E.; Tassi, R. A.; Calza, S.; Ravaggi, A.; Bandiera, E.; Rossi, E.; Donzelli, C.; Pasinetti, B.; Pecorelli, S. \& Santin, A. D. Gene expression profile of ovarian serous papillary carcinomas: identification of metastasis-associated genes. Am. J. Obstet. Gynecol., 196(3):245,e1-11, 2007.
Cheng, N.; Bhowmick, N. A.; Chytil, A.; Gorksa, A. E.; Brown, K. A.; Muraoka, R.; Arteaga, C. L.; Neilson, E. G.; Hayward, S. W. \& Moses H. L. Loss of TGF-beta type II receptor in fibroblasts promotes mammary carcinoma growth and invasion through upregulation of TGF-alpha-, MSP-and HGF-mediated signaling networks. Oncogene, 24(32):5053-68, 2005.

Dvorak, H. F. Angiogenesis: update 2005. J. Thromb. Haemost., 3(8):1835-42, 2005.

García-Ocaña, M.; Vázquez, F.; García- Pravia, C.; FuentesMartínez, N.; Menéndez-Rodríguez, P.; Fresno-Forcelledo, F.; Barneo-Serra, L.; Del Amo Iribarren, J.; Simón-Buela, L. \& De Los Toyos, J. R. Characterization of a novel mouse monoclonal antibody, clone 1E8.33, highly specific for human procollagen 11A1, a tumor-associated stromal component. Int. J. Oncol., 40(5):1447-54, 2012. 
Greco, F .A. \& Hainsworth J. D. Introduction: unknown primary cancer. Semin. Oncol., 36(1):6-7, 2009.

Kalluri, R. \& Weinberg, R. A. The basics of epithelial-mesenchymal transition. J. Clin. Invest., 119(6):1420-8, 2009.

Kim, H.; Watkinson, J.; Varadan, V. \& Anastassiou, D. Multi-cancer computational analysis reveals invasion-associated variant of desmoplastic reaction involving INHBA, THBS2 and COL11A1. BMC Med. Genomics, 3:51, 2010.

Kowalski, P. J.; Rubin, M. A. \& Kleer, C. G. E-cadherin expression in primary carcinomas of the breast and its distant metastases. Breast Cancer Res., 5(6):R217- 22, 2003.

Lewis, C. E. \& Pollard, J. W. Distinct role of macrophages in different tumor microenvironments. Cancer Res., 66(2):60512, 2006.

Malanchi, I.; Santamaría-Martínez, A.; Susanto, E.; Peng, H.; Lehr, H. A.; Delaloye, J. F. \& Huelsken, J. Interactions between cancer stem cells and their niche govern metastatic colonization. Nature, 481(7379):85-9, 2012.

Mani, S. A.; Guo, W.; Liao, M. J.; Eaton, E. N.; Ayyanan, A.; Zhou, A. Y.; Brooks, M.; Reinhard, F.; Zhang, C. C.; Shipitsin, M.; Campbell, L. L.; Polyak, K.; Brisken, C.; Yang, J. \& Weinberg R. A. The epithelial-mesenchymal transition generates cells with properties of stem cells. Cell, 133(4):704-15, 2008.

Mohamed, M. M. \& Sloane, B. F. Cysteine cathepsins: multifunctional enzymes in cancer. Nat. Rev. Cancer, 6(10):764-75, 2006.

Omary, M. B.; Coulombe, P. A. \& McLean, W. H. Intermediate filament proteins and their associated diseases. N. Engl. J. Med., 351(20):2087-100, 2004.

Orimo, A.; Gupta, P. B.; Sgroi, D. C.; Arenzana-Seisdedos, F.; Delaunay T.; Naeem, R.; Carey, V. J.; Richardson, A. L. \& Weinberg, R. A. Stromal fibroblasts present in invasive human breast carcinomas promote tumor growth and angiogenesis through elevated SDF-1/CXCL12 secretion. Cell, 121(3):33548,2005

Pantel, K.; Brakenhoff, R. H. \& Brandt, B. Detection, clinical relevance and specific biological properties of disseminating tumour cells. Nat. Rev. Cancer, 8(5):329-40, 2008.

Raviraj, V.; Zhang, H.; Chien, H. Y.; Cole, L.; Thompson, E. W. \& Soon, L. Dormant but migratory tumour cells in desmoplastic stroma of invasive ductal carcinomas. Clin. Exp. Metastasis, 29(3):273-92, 2012

Rhim, A. D.; Mirek, E. T.; Aiello, N. M.; Maitra, A.; Bailey, J. M.; McAllister, F.; Reichert, M.; Beatty, G. L.; Rustgi, A. K.; Vonderheide, R. H.; Leach, S. D. \& Stanger, B. Z. EMT and dissemination precede pancreatic tumor formation. Cell, $148(1$ 2):349-61, 2012.
Song, J. EMT or apoptosis: a decision for TGF-beta. Cell Res., 17(4):289-90, 2007.

Tse, J. C. \& Kalluri, R. Mechanisms of metastasis: epithelial-tomesenchymal transition and contribution of tumor microenvironment. J. Cell Biochem., 101(4):816-29, 2007.

Voulgari, A. \& Pintzas, A. Epithelial-mesenchymal transition in cancer metastasis: mechanisms, markers and strategies to overcome drug resistance in the clinic. Biochim. Biophys. Acta, 1796(2):75-90, 2009.

Yang, J. \& Weinberg, R. A. Epithelial-mesenchymal transition: at the crossroads of development and tumor metastasis. Dev. Cell, 14(6):818-29, 2008.

Zeisberg, M. \& Neilson, E. G. Biomarkers for epithelialmesenchymal transitions. J. Clin. Invest., 119(6):1429-37, 2009.

\section{Correspondence to:}

Patricia Castro-Santos, PhD.

Facultad de Ciencias de la Salud

Universidad Autónoma de Chile

5 Poniente $n^{\circ} 1670$, Talca

CHILE

Email: pcastros@uautonoma.cl

Received: 14-12-2013

Accepted: 23-05-2014 